\title{
DIAGNÓSTICO DA APLICAÇÃO DO LICENCIAMENTO AMBIENTAL PARA EMPREENDIMENTOS DE PISCICULTURA EM UM MUNICÍPIO DO MATO GROSSO DO SUL
}

Tamires Cristiane Tramarin*

Renata Ruaro**

RESUMO: A piscicultura é uma alternativa econômica emergente no Brasil. No Estado de Mato Grosso do Sul as condições hidrológicas e climáticas contribuem para o desenvolvimento dessa atividade, a qual proporciona rendimento aos pequenos e grandes produtores. Por ser uma atividade que depende dos recursos naturais, é considerada potencialmente poluidora, de forma que é necessário que seja tutelada por instrumentos legais para alcançar desenvolvimento produtivo e, principalmente, a proteção ambiental. O licenciamento ambiental é um instrumento que autoriza a prática dessas atividades, pois estabelece regras e medidas que visam minimizar os impactos ao ambiente. Os objetivos deste trabalho foram identificar a aplicação do licenciamento ambiental no município de Mundo Novo - Mato Grosso do Sul - e diagnosticar possíveis problemas que dificultam a sua obtenção. Além disso, objetivou-se verificar o nível de informação dos piscicultores a respeito desse instrumento e dos possíveis impactos ambientais, bem como a existência de apoio técnico e subsídios para a expansão da atividade. Para a coleta de dados, foram realizadas visitas às propriedades com aplicação de um questionário estruturado com 37 questões subdivididas em relação aos temas voltados à caracterização geral da piscicultura e ao licenciamento ambiental. Os resultados demonstraram que todos os piscicultores possuem licença, porém a grande maioria desconhece o que isso representa realmente, além disso desconhecem os impactos ambientais provenientes da piscicultura. Os resultados evidenciaram ainda que o maior entrave na obtenção desse instrumento é a morosidade na emissão de licenças que está relacionada diretamente à centralização de competência e processos e, ainda, à insuficiência de profissionais capacitados.

PALAVRAS-CHAVE: Preservação ambiental; Licenciamento ambiental; Impactos ambientais.

** Doutoranda no Programa de Pós-graduação em Ecologia de Ambientes Aquáticos Continentais pela Universidade Estadual da Maringá (UEM), Brasil. E-mail: renataruaro_@hotmail.com 


\section{DIAGNOSIS OF ENVIRONMENTAL WARRANT FOR PISCICULTURE ENTERPRISES IN A MUNICIPALIT Y OF MATO GROSSO DO SUL, BRAZIL}

ABSTRACT: Pisciculture is an emergent economic activity in Brazil. Hydrological and climatic conditions in the state of Mato Grosso do Sul, Brazil, are highly propitious for such activities, with profit for small- and big-sized producers. Since it depends on natural resources, it is potentially pollutant and should be monitored by legislation for productive development and environmental protection. Environmental warrant authorizes pisciculture activities since it establishes rules that lessen impacts on the environment. Current paper identifies the application of environmental warrant in the municipality of Mundo Novo MS Brazil, and diagnoses possible problems which impede obtaining it. Information that fish breeders have on the warrant, environmental impacts, technical support and subsidies for its expansion are identified. Data were collected by applying a 37-question questionnaire subdivided into themes on pisciculture in general and environmental warranting. Results showed that all fish breeders have a warrant but most are unaware what it really means. They are also unaware of environmental impacts caused by pisciculture. The greatest impairment is delay in obtaining the warrant directly related to the centralization of competence, processes and scarcity of capacitated professionals.

KEY WORDS: Environmental preservation; Environmental warrant; Environmental impact.

\section{INTRODUÇÃO}

A piscicultura brasileira instalou-se como uma atividade econômica na produção de alimentos e é considerada uma atividade vantajosa, destacando a eficiência no uso das áreas improdutivas, na manutenção da atividade, a rapidez no retorno investido e a alta produção por área, além de ser ótima fonte de alimentação (ARAÚJO; MORAES, 2010). Além disso a carne do peixe é um dos produtos alimentares mais negociados mundialmente, e cerca de 35\% de toda proteína animal consumida provém de pescados (CARVALHO, 2009),

O Estado de Mato Grosso do Sul (MS) possui características favoráveis ao desenvolvimento da piscicultura, tanto em relação aos aspectos geomorfológicos 
quanto climáticos, fatores que contribuem para a instalação de tanques e bom desenvolvimento da atividade na região (RESENDE, 2007). Embora a piscicultura tenha se estabelecido gradativamente, promovendo o desenvolvimento econômico e social, apoiada por investimentos do setor produtivo e do governo (TAKAHASHI et al., 2008), ela tem se caracterizado como um desafio para a gestão ambiental, pela expansão dessa atividade e insuficiência de técnicas de manejo adequado no que tange à preservação ambiental.

A piscicultura depende essencialmente dos recursos naturais do local em que está inserida. Embora seja impossível desenvolvê-la sem provocar impactos ambientais, é possível reduzi-los, evitando o esgotamento e alterações na qualidade ambiental (SOARES, 2003). Desse modo, a preocupação com a qualidade e preservação do ambiente deve ser prioridade, desde os primeiros passos do planejamento da atividade, diminuindo os possíveis prejuízos ao ambiente e consequentemente refletindo na qualidade da produção.

É necessário conhecer e adequar-se à legislação vigente de modo a prevenir a degradação dos recursos naturais e as consequentes multas por crimes ambientais. Uma das principais leis ambientais é a Política Nacional do Meio Ambiente (PNMA), lei federal 6.938, de 31 de agosto de 1981. A PNMA definiu que toda atividade com potencial poluidor, que pode interferir na qualidade de vida e no equilíbrio ambiental, estará sujeita ao licenciamento ambiental (LA). O LA é um procedimento administrativo pelo qual o órgão ambiental autoriza a localização, instalação, ampliação e operação de empreendimentos e atividades utilizadoras de recursos ambientais, que possam causar degradação ambiental.

A resolução CONAMA n ${ }^{0}$ 237, de 19 de dezembro de 1997, explana todas as etapas do processo de LA que é, em geral, composto por Licença Prévia (LP), Licença de Instalação (LI) e Licença de Operação (LO). A Licença Prévia aprova a localização e concepção do empreendimento ou atividade e ainda atesta a sua viabilidade ambiental. O órgão licenciador avalia se a localização do empreendimento é apropriada, levando em consideração os impactos ambientais (considerando o meio físico, biótico e socioeconômico). Caso seja necessário, pode ser realizada uma audiência pública para discutir os possíveis impactos ambientais e as medidas mitigadoras e compensatórias com a comunidade. Após a obtenção da LP, o 
empreendedor solicita a LI. É verificado se todas as condicionantes foram atendidas, então, o órgão competente autoriza a construção e a instalação de equipamentos do empreendimento, podendo ainda ser estabelecidas outras condicionantes. Por fim, a Licença de Operação autoriza o início das atividades, após a verificação do cumprimento às licenças preliminares e suas condicionantes.

Além dessas licenças (LP, LI e LO), podem existir outros tipos de acordo com porte do empreendimento, atividade e normas de cada Estado brasileiro. No Estado do MS, a resolução SEMAC 008, de 31 de maio de 2011, estabelece normas e procedimentos para a LA no Estado e determina que as atividades consideradas de baixo potencial ofensivo ao ambiente estão sujeitas ao licenciamento ambiental simplificado (LAS), no qual a LP, LI e LO são concedidas simultaneamente com a emissão de apenas um documento. O Instituto de Meio Ambiente de Mato Grosso do Sul (IMASUL) é o órgão competente que emite a concessão da licença e executa a fiscalização de atividades efetivas ou potencialmente poluidoras ao ambiente. Contudo alguns munícipios do Estado, como Amambai, Campo Grande, Itaquiraí, Naviraí, Ponta Porã, Três lagoas e Dourados, possuem competência para LA de atividades consideradas de impacto local.

Assim, este trabalho objetivou identificar a aplicação da LA e diagnosticar os possíveis desafios que os piscicultores do município de Mundo Novo/MS encontram para a obtenção LA. Além disso, foram obtidas informações a respeito do nível de conhecimento que os piscicultores possuíam sobre a LA. O tema do estudo é de especial importância para o desenvolvimento sustentável da piscicultura no município e na região sul do Estado, visto que é uma atividade em expansão e necessita de controle para que seja possível a sua continuidade. A obtenção de informações a respeito da LA pode contribuir para delinear as lacunas e dificuldades dos produtores na busca de melhorias nas técnicas de manejo. 


\section{MATERIAL E MÉTODOS}

\section{1 ÁREA DE ESTUDO}

O estudo foi desenvolvido no município de Mundo Novo - MS, o qual possui uma população de 17.658 habitantes e área territorial de $477,780 \mathrm{~km}^{2}$ (IBGE, 2014), fazendo divisa com o Estado do Paraná e o país Paraguai. As propriedades pesquisadas encontram-se na sua totalidade em área rural.

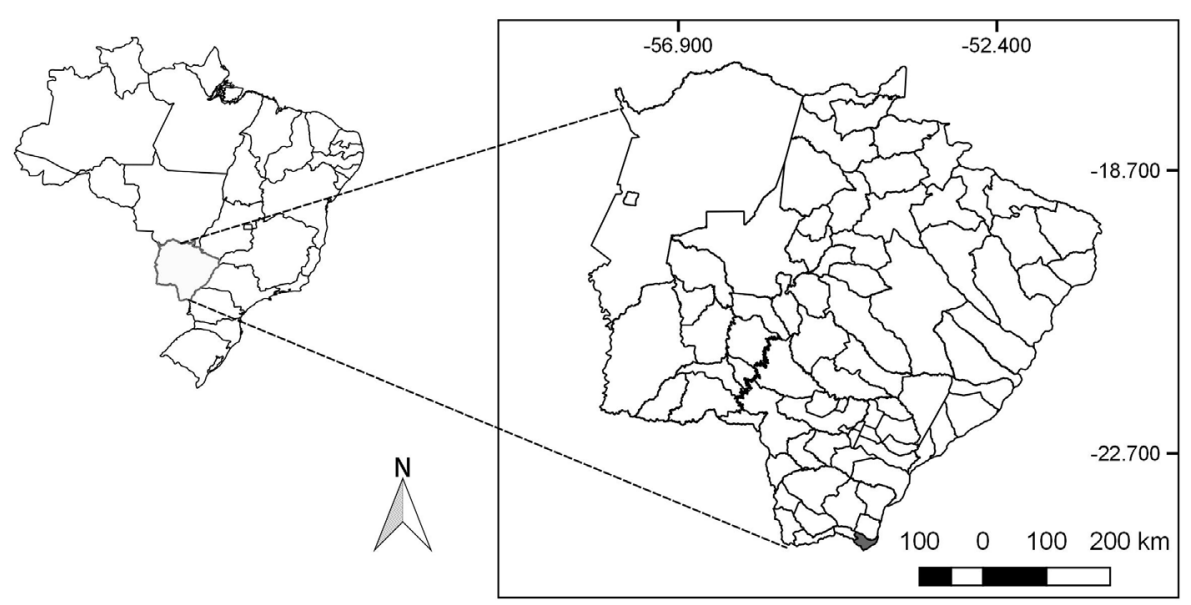

Figura 1. Localização da área de estudo. Área do município de Mundo Novo- MS, destacada em cinza.

Desde 1999, os piscicultores de Mundo Novo se organizam em uma cooperativa, criada com o intuito de melhorar as vendas, e, assim, terem sua própria indústria de pescados e consequentemente a elevação dos lucros. A COOPISC Cooperativa de Piscicultores de Mundo Novo - possui atualmente 20 piscicultores cadastrados, dos quais 17 foram contemplados pelo presente estudo, os outros três restantes estão em processo de desativação e não produzem há mais de dois meses, portanto, não fizeram parte da pesquisa. 


\subsection{COLETA DE DADOS}

Este trabalho foi realizado com base em uma pesquisa descritiva qualitativa (PRODANOV; FREITAS, 2013). Para a coleta de dados, foi realizada entrevista estruturada com o auxílio de questionário, com perguntas pré-elaboradas em uma ordem de sequência de acordo com o tema da pesquisa. No questionário, as questões foram divididas em blocos em relação ao assunto abordado. Incialmente foram levantadas informações para caracterizar o perfil dos produtores (como escolaridade por satisfação e dificuldades relacionadas ao desenvolvimento da atividade). Na sequência, foram abordadas questões para a caracterização: a) da propriedade (como posse, mão de obra, tipo de atividade e outras atividades envolvidas com a piscicultura), b) da piscicultura (como tipo de estrutura, lâmina d'água, número de tanques, origem da água e destino dos efluentes), c) da produção (como sistema de produção, volume mensal, espécies cultivadas, sistemas de alimentação e tipo de comercialização). Por fim, foram abordadas as informações relativas à LA, à percepção quanto aos impactos ambientais e a opinião dos piscicultores, referente às melhorias para melhor gestão da atividade.

A pesquisa de campo foi realizada no mês de junho de 2014. Um total de 12 propriedades foram visitadas, e os questionários foram aplicados a 17 piscicultores, tendo-se em vista que havia propriedades com mais de um produtor cadastrado.

\section{RESULTADOS E DISCUSSÃO}

\subsection{PERFIL DO PROPRIETÁRIO}

Dos piscicultores pesquisados, $11 \%$ possuíam o ensino fundamental e exerciam a atividade havia menos de dez anos, enquanto que $72 \%$ possuíam o ensino médio e exerciam a atividade havia mais de dez anos. Apenas 17\% possuíam nível superior completo, e esses piscicultores trabalhavam havia mais de 15 anos na atividade. Isso evidencia que o tempo de atividade, o maior grau de instrução e a qualificação profissional podem contribuir para a continuidade e expansão da 
atividade. Segundo Pimenta (2012), muitos piscicultores buscam a qualificação profissional, mesmo que seja de alto custo, pois entendem que a capacitação é muito importante para o desenvolvimento e aprimoramento da atividade.

Em relação à satisfação do retorno da atividade, todos os entrevistados acreditam que a atividade é rentável e vale a pena investir, porém listaram algumas dificuldades, como falta de incentivo comercial, burocratização de acesso ao crédito e alto custo na implantação e operação da atividade. A falta de incentivo comercial relatada deve-se possivelmente ao fato de que o frigorífico local está desativado e a demora de iniciativa por parte dos governos municipal e estadual está impedindo $\mathrm{o}$ aumento da produção e comercialização. O frigorífico em funcionamento possibilitaria aos cooperados a estocagem do produto e melhoria na comercialização. A instalação de um frigorífero agrega valor ao produto e aumenta a competitividade no mercado, pois aumenta a confiança do consumidor que opta por produtos inspecionados (CASTRO et al., 2011).

\subsection{CARACTERIZAÇÃO DA PROPRIEDADE}

De todas as propriedades pesquisadas, somente duas delas eram arrendadas, as demais eram próprias e, na grande maioria, o tipo de mão de obra era familiar (88\%), nas restantes, era contratada. A contratação surge especialmente nas épocas de despescas, quando o peixe é retirado para venda, ou para limpeza e manutenção dos tanques. Observa-se que a geração de emprego pela atividade é predominantemente familiar, fato que gera renda local e contribui para a economia regional, desse modo deve ser amparada e incentivada por políticas públicas de incentivo à atividade (GUILHOTO et al., 2007). Em todas as propriedades a atividade destina-se a fins comerciais, em que a piscicultura consiste na principal fonte de renda familiar, ressaltando a importância da atividade no município.

Em todas as propriedades pesquisadas, a única atividade realizada é a piscicultura, não havendo outra atividade que auxilie na renda do produtor, o que mostra a importância social e econômica da atividade. Esse resultado, obtido em Mundo Novo - MS, difere bastante do diagnóstico feito na bacia do Alto Taquari-MS, onde 54 produtores têm a pecuária como atividade predominante, enquanto que a piscicultura é realizada apenas como complemento de renda (ROTTA, 2003). A piscicultura é considerada potencialmente promissora para o desenvolvimento do 
Estado (BATISTA, 2013), por isso as oportunidades devem ser aproveitadas uma vez que o Estado de Mato Grosso do Sul possui características propícias ao cultivo.

\subsection{CARACTERIZAÇÃO DA PISCICULTURA}

Em todas as propriedades o tipo de estrutura era de tanque escavado, (tanques feitos de terra que apresentam condições próximas às naturais dos peixes, dotados de sistema de abastecimento e drenagem de água). Essa estrutura leva em consideração a tipologia do solo e a origem da água e é considerada muito eficiente porque possibilita um manejo mais apurado pelo produtor (INOUE; BOUJINK, 2011).

Em relação à origem da água na atividade, foi observado que $70 \%$ eram provenientes de córregos, dentre eles, os córregos Santa Maria e Guassú, e 30\% de nascentes localizadas na própria propriedade. Isso destaca a importância dos recursos hídricos para o desenvolvimento e manutenção da atividade, mas, por outro lado, ressalta o potencial de geração de impactos ao ambiente. Um dos aspectos mais importantes e complexos da piscicultura envolve a manutenção da qualidade da água em condições adequadas para a criação dos organismos aquáticos, demandando manejo efetivo para a minimização dos impactos, seja na captação ou no lançamento de efluentes (MACEDO; SIPAÚBA-TAVARES, 2010).

$\mathrm{O}$ número de tanques nas propriedades apresentou-se muito variável, a propriedade com menor quantidade continha apenas três tanques, enquanto que a maior, 35. Esses resultados estão relacionados à disponibilidade de terras e recursos para a ampliação. Em algumas propriedades não existem mais espaços para a escavação de tanques e em outras o problema reside na falta de recursos para investir. Em relação à lâmina d'água, a maioria dos piscicultores possui mais de 15 ha (Tabela 1), o que é considerado pela resolução Conama 413/09 como de porte médio e alto impacto ambiental, fato que justifica a obrigatoriedade de LA. 
Tabela 1. Área das pisciculturas por lâmina d'água e número de produtores

\begin{tabular}{l|c|c}
\hline Área de lâmina d'água & Número de produtores & Percentual (\%) \\
\hline Área menor que 1 ha & 4 & 23 \\
\hline Área entre 1 ha a 3 ha & 4 & 23 \\
\hline Área entre 7,1 ha e 9 ha & 2 & 12 \\
\hline Área com mais de 15 ha & 7 & 42 \\
\hline
\end{tabular}

Um aspecto importante foi o destino dos efluentes, os produtores com menor área de produção não tinham nenhum tipo de tratamento, ou desconheciam a necessidade de fazê-lo, argumentando que, para a criação de peixes, a água deveria estar em perfeitas condições e consequentemente sair dos tanques sem alterações para os corpos d'água receptores. Esses resultados evidenciam falta de informação dos piscicultores a respeito dos resíduos gerados pela atividade e os respectivos impactos, pois as características do efluente gerado pela piscicultura são semelhantes àquelas do esgoto doméstico, com elevada demanda bioquímica de oxigênio, alta concentração de sólidos em suspensão, compostos nitrogenados e fosfatados, contribuindo para a eutrofização dos rios (ZANIBONI FILHO, 2005).

Contudo a preocupação em diminuir os impactos não deve começar no tratamento de efluentes, mas sim no manejo alimentar. O nitrogênio dos efluentes da atividade provém principalmente da proteína da ração, que é o principal alimento dos peixes (CYRINO et al., 2010). Para diminuir os impactos negativos, deve-se utilizar ração de boa qualidade e implementar ações adequadas de manejo alimentar, característico para cada fase de crescimento e tipo de espécie (MALLASEN, 2012).

Os produtores com maiores áreas de cultivo apresentaram ciência da necessidade e importância de tratar os efluentes. Em 76\% das propriedades que adotam sistema de tratamento, a técnica utilizada é a de Wetlands construídos, que funciona como um filtro biológico, em que as macrófitas são as responsáveis pela depuração da água, absorvendo os nutrientes e armazenando-os em seus tecidos (HENRY-SILVA; CARMARGO, 2008). Os estudos sobre o uso de Wetlands construídas no tratamento do efluente da piscicultura evidenciam a eficácia dessa tecnologia na remoção de nitrogênio, fósforo, matéria orgânica e material particulado (BIUDES; 
CAMARGO, 2007). As propriedades que fazem o tratamento de efluentes por meio dessa metodologia possuem um corredor construído artificialmente no qual o efluente percorre um trajeto até chegar ao corpo receptor, nesse trecho os resíduos entram em contato com as plantas aquáticas.

A ausência de indicadores para o monitoramento ambiental da piscicultura é considerada um desafio para a gestão ambiental, principalmente porque esses indicadores precisam ser viáveis e eficientes para que possam ser adotados pelos piscicultores (SAMPAIO et al., 2003). Essa seleção e adoção de indicadores resultariam em instrumentos de gestão e adequação de práticas sustentáveis não somente no tratamento de efluentes, mas em todos os processos da atividade.

O monitoramento dos efluentes nas pisciculturas pesquisadas não é contínuo. Somente em duas propriedades pesquisadas esse monitoramento foi realizado e apenas uma única vez por órgãos ambientais de fiscalização, nas demais nunca houve nenhuma atividade de monitoramento. Quando indagados se não poderiam realizar o monitoramento, os piscicultores afirmaram que não tinham conhecimento dos procedimentos e que não possuíam condições nem recursos financeiros para arcar com o serviço. Em geral, o que tem sido feito pelos piscicultores é somente o monitoramento da qualidade da água nos tanques, em que são monitorados parâmetros como oxigênio, temperatura, $\mathrm{pH}$, amônia, para a verificação das condições ótimas para o desenvolvimento dos peixes.

\subsection{CARACTERIZAÇÃO DA PRODUÇÃO}

Foram observados dois tipos de sistema de produção, o semi-intensivo, em $30 \%$, e o intensivo em $70 \%$ das propriedades. O sistema intensivo é o mais adotado já que proporciona alta produção e todas as propriedades possuem fins comerciais. Esses sistemas estão diretamente relacionados à elevada densidade de peixes por volume d'água e adoção de técnicas de manejo e produção. De acordo com a resolução Conama 413, de 26 de junho de 2009, no sistema de cultivo intensivo as espécies dependem essencialmente de alimento artificial, enquanto que no sistema de cultivo extensivo as espécies cultivadas são tratadas com alimento natural e com pouca utilização de insumos.

No sistema semi-intensivo, em que as espécies dependem principalmente 
de alimento artificial, a produtividade anual pode chegar a $5.500 \mathrm{~kg}$ de peixe/ha, enquanto que no sistema intensivo a produtividade média anual varia entre 6.000 e $15.000 \mathrm{~kg} / \mathrm{ha}$ (BALDISSEROTTO, 2009). Assim, considerando-se os resultados obtidos (70\% como cultivo intensivo), pode-se estimar que a média de produção anual dos piscicultores de Mundo Novo gira em torno de $13.000 \mathrm{~kg} / \mathrm{ha}$.

A respeito do sistema de alimentação, todos os piscicultores fazem uso da ração comercial. Em $24 \%$ das propriedades, a produção é voltada para recria e engorda, e as demais, somente para a engorda. Os piscicultores adquirem os alevinos que permanecem na propriedade até atingirem o ponto de comercialização. A produção é vendida para pesque-pague e para frigoríficos da região, já que o frigorífico local ainda não está em operação. Quando questionados a respeito do interesse em aumentar a produção, todos os piscicultores afirmaram que não pretendem aumentar a produção, justificam isso à satisfação atual e também porque isso implicaria em gastos e áreas insuficientes, fatores limitantes para a maioria das propriedades estudadas.

Dentre as espécies cultivadas, destacam-se o pacu (Piaractus mesopotamicus), a tilápia (Oreochromis niloticus), o bagre (Luciopimelodus platanus), a carpa comum (Cyprinus carpio), o pintado (hibrído - Leiarius marmoratus $x$ Pseudoplatystoma corruscans) e o catfish (Ictalurus punctatus). Destas, somente o pacu é nativa (Tabela 2). Segundo Scorvo Filho (2003), a crescente introdução de espécies não nativas possibilita alta produção e facilidade de venda, pensamento compartilhado pelos piscicultores entrevistados. Além disso espécies como tilápia e catfish possuem avançado conhecimento de manejo e biologia, se comparados a algumas espécies nativas (SILVA et al., 2008).

Tabela 2. Espécies cultivadas nas propriedades avaliadas

(Continua)

\begin{tabular}{c|c|c|c|c|c}
\hline $\mathbf{N}^{\mathbf{0}}$ & $\begin{array}{c}\text { Nome } \\
\text { popular }\end{array}$ & Nome científico & $\begin{array}{c}\text { Espécie } \\
\text { nativa }\end{array}$ & $\begin{array}{c}\text { Espécie não } \\
\text { nativa }\end{array}$ & $\begin{array}{c}\mathbf{N}^{\mathbf{0}} \mathbf{d e} \\
\text { produtores }\end{array}$ \\
\hline $\mathbf{1}$ & Pacu & Piaractus mesopotamicus & $\mathrm{X}$ & & 14 \\
\hline $\mathbf{2}$ & Tilápia & Oreochromis niloticus & & $\mathrm{X}$ & 17 \\
\hline $\mathbf{3}$ & Bagre & Luciopimelodus platanus & & $\mathrm{X}$ & 5
\end{tabular}


Diagnóstico da aplicação do licenciamento ambiental para empreendimentos de piscicul...

\begin{tabular}{l|c|c|c|c|c}
$\mathbf{N}^{\mathbf{2}}$ & $\begin{array}{c}\text { Nome } \\
\text { popular }\end{array}$ & Nome científico & $\begin{array}{c}\text { Espécie } \\
\text { nativa }\end{array}$ & $\begin{array}{c}\text { Espécie não } \\
\text { nativa }\end{array}$ & $\begin{array}{c}\mathbf{N}^{\mathbf{0}} \text { de } \\
\text { produtores }\end{array}$ \\
\hline $\mathbf{4}$ & $\begin{array}{c}\text { Carpa } \\
\text { comum }\end{array}$ & Cyprinus carpio & $\mathrm{X}$ & 4 \\
\hline $\mathbf{5}$ & Pintado & $\begin{array}{c}\text { Leiarius marmoratus } x \\
\text { Pseudoplatystoma corruscans }\end{array}$ & & $\mathrm{X}$ & 8 \\
\hline $\mathbf{6}$ & Catfish & Ictalurus punctatus & & $\mathrm{X}$ & 17 \\
\hline
\end{tabular}

\subsection{LICENCIAMENTO AMBIENTAL}

Perguntados quanto ao conhecimento sobre as leis ambientais vigentes que regem a piscicultura, $100 \%$ dos piscicultores disseram ter no mínimo tido algum tipo de informação a respeito, e a resposta da maioria foi de que, sem a LAl, não poderiam exercer a atividade. Todos os produtores possuem LA e a obtiveram desde o início da atividade; $47,05 \%$ possuem a LAS, por serem considerados de pequeno porte com menos de 5 ha de lâmina d água; 11,78\% dos produtores encontram-se em processo de renovação da LO; e 41,17\% estão com a LO em vigência. A única dificuldade relatada por todos foi a demora na obtenção da licença, tendo-se em vista que a obtenção de cada licença (LP, LI, e LO ou LAS) demora em média de oito a 12 meses, e, considerando-se que na LA convencional é necessária a obtenção das três (LP, LI, e LO), esse processo pode demorar cerca de três anos.

O município de Mundo Novo não possui nenhum instrumento de cooperação com o órgão estadual do meio ambiente para delegação de competência de LA, de modo que os técnicos da AGRAER instruem os piscicultores e encaminham os documentos requeridos ao IMASUL na unidade regional de Dourados que é a mais próxima de Mundo Novo, cerca de $249 \mathrm{~km}$. O problema não é particular do município, segundo um estudo realizado por Dotti et al. (2012), no município de Dourados-MS, as maiores dificuldades relatadas pelos piscicultores foram a morosidade do processo e a demora entre o pedido e a vistoria. Segundo os autores, esse problema evidencia a pouca quantidade de funcionários dos órgãos ambientais que não suprem a demanda de vistoria e fiscalização.

A respeito dos benefícios adquiridos pela regularização ambiental, os produtores destacaram principalmente as políticas públicas de fomento, como o 
financiamento e a isenção fiscal, e associação à cooperativa (Figura 2). Somente dois produtores evidenciaram como benefícios da LA a proteção e preservação ambiental. Esse dado revela ausência de conhecimento sobre os possíveis efeitos negativos da piscicultura nos recursos naturais e dos propósitos da regularização para a manutenção da qualidade ambiental. Segundo o Sebrae (2011), a regularização proporciona condições de orientar os empreendimentos para uma atuação sustentável, de modo a atender também aos mercados que se tornam cada vez mais exigentes quanto aos aspectos ambientais e sanitários.

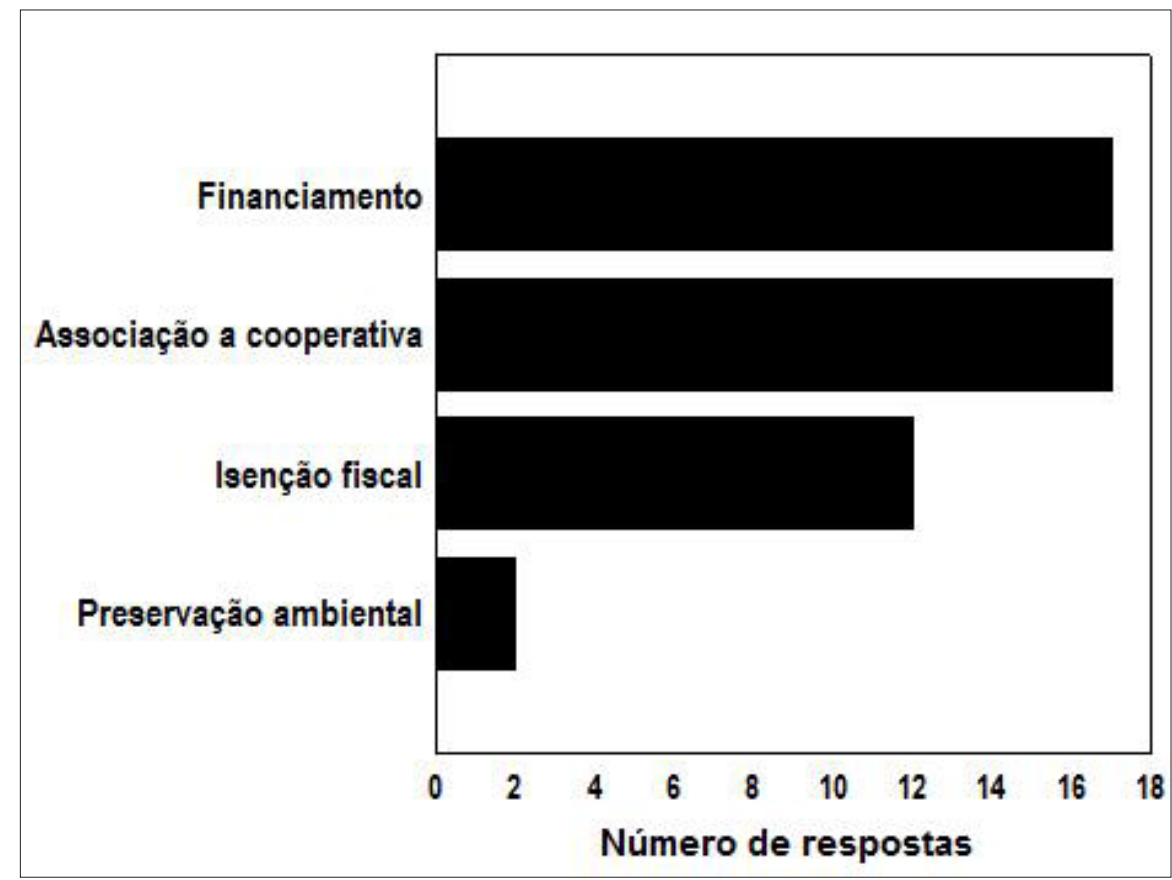

Figura 2. Benefícios do licenciamento ambiental, segundo os piscicultores de Mundo Novo -MS

Quanto à assistência técnica, todos os entrevistados disseram ter tido algum tipo de assistência, fosse na documentação do projeto, ou em relação às técnicas de manejo e produção. De acordo com Dutra (2014), no município de Dourados MS, a realidade é diferente, a falta de assistência técnica é uma queixa recorrente, pois os piscicultores recebem assistência somente na elaboração de projetos. Quando ocorrem problemas na produção, eles recorrem aos demais produtores, que 
repassam conhecimentos baseados em experiências vivenciadas nas propriedades.

Nenhum dos piscicultores afirmou arcar com gastos em assistência, pois todos foram atendidos por técnicos da Agraer e de empresas fornecedoras de ração que disponibilizam assistência sem custos adicionais. Isso ocorre pois a falta de conhecimento técnico é uma das maiores causas de abandono e fracasso na atividade, tendo-se em vista que muitos iniciam a atividade sem critérios técnicos e ambientais, o que, em médio e longo prazo, acaba comprometendo tanto os recursos disponíveis quanto a qualidade da produção (APPOLO; NISHIJIMA, 2011).

\subsection{PERCEPÇÃO QUANTO AOS IMPACTOS AMBIENTAIS}

A respeito do conhecimento do piscicultor sobre a geração de impactos ambientais, vinculados à atividade, 47,1\% afirmaram que desconhecem qualquer tipo de dano ao ambiente e, além disso, responderam desconhecer que espécies não nativas podem causar problemas ambientais. Os outros 52,9\% afirmaram conhecer, mesmo que superficialmente, possíveis impactos ao ambiente. Segundo Valenti (2002), os impactos ambientais relacionados à piscicultura ocorrem durante as fases de implantação e operação, tais como a remoção da cobertura vegetal, remoção de mata ciliar, liberação de efluentes ricos em nutrientes que pode causar eutrofização em corpos d'água naturais, introdução de espécies exóticas e doenças no ambiente.

Em relação às espécies não nativas, um piscicultor afirmou que todos os piscicultores possuem algum conhecimento sobre os impactos, mesmo que de modo superficial, porém, segundo ele, não há alternativas aos piscicultores, ou se cultivam espécies não nativas ou se abandona a atividade. Além disso esse piscicultor afirmou que os demais sabem pouco sobre esses impactos, porque os resultados das pesquisas não chegam até eles de forma clara. Sabe-se que a introdução de espécies não nativas pode gerar diversos impactos como a extinção de espécies nativas, alteração de habitats, predação e ainda transmissão de patógenos (DELARIVA; AGOSTINHO, 1999). No entanto o Brasil é considerado um dos maiores produtores de espécies não nativas e não tem dado atenção ao desenvolvimento de pesquisas e tecnologias para o cultivo de espécies nativas (LIMA JUNIOR et al., 2012), o que dificulta ainda mais a inserção dessas espécies pelos piscicultores, embora na 
maioria dos córregos e rios receptores do território nacional as espécies não nativas já estejam inseridas pela pesca esportiva, pela aquariofilia e pela própria piscicultura (LANGEANI et al., 2007).

Em relação às áreas de preservação permanente (APPs), 17\% responderam que não tinham ideia do que significava, embora possuíssem APPs em sua propriedade. Por outro lado, $82 \%$ responderam que sabiam o que essas áreas representavam. Em todas as propriedades havia nascentes. De acordo com o novo código florestal, compõe área de preservação permanente a área localizada ao redor de nascente, com raio mínimo de proteção vegetal de 50m (BRASIL, 2012). Porém o que se observou foi que em nenhuma propriedade os parâmetros, definições e limites de APP estavam sendo respeitados, tendo-se em vista que em algumas propriedades essa área não chegava a $3 \mathrm{~m}$.

Essa situação é alarmante visto que a vegetação em torno da nascente desempenha funções importantes para a conservação dos recursos naturais e manutenção da qualidade ambiental, como a retenção de sedimentos e controle do processo erosivo (GOMES et al., 2005). Sem a devida composição vegetal em torno das nascentes pode ocorrer futuramente o comprometimento da atividade já que $30 \%$ dos tanques de peixes utilizam água proveniente de nascentes.

\subsection{OPINIÕES DOS PISCICULTORES PARA MELHORIA DA ATIVIDADE}

A respeito do que poderia ser feito para melhorar a qualidade e produção da atividade, notou-se que cada piscicultor tinha uma opinião em particular, relacionada às condições de cada um. Entretanto alguns aspectos foram abordados por todos como assistência técnica especializada que proporcione suporte e auxílio em melhorias para o manejo; maior incentivo financeiro do governo; desburocratização e agilidade das licenças ambientais. Esses dados manifestam a intenção de melhoria no desenvolvimento da atividade em relação à produção, contudo ainda não está introduzido nesse conjunto de aprimoramentos o interesse objetivo, relacionado ao ambiente, provavelmente pela falta de conhecimento mais aprofundado de técnicas de manejo sustentáveis e, por vezes, por se acreditar que o manejo executado é suficiente. 


\section{CONSIDERAÇÕES FINAIS}

Este trabalho demonstrou que em Mundo Novo - MS os piscicultores atendem à LA, mesmo desconhecendo a importância e o que isso representa. Além disso este estudo evidenciou que os piscicultores desconhecem os possíveis impactos ambientais, decorrentes da atividade, e consequentemente não realizam medidas para minimizá-los. Isso é preocupante, uma vez que os impactos relacionados à piscicultura como lançamento de efluentes, introdução de espécies não nativas e supressão das áreas de preservação permanente possuem riscos ao ambiente e à produção. Nesse sentido, as pisciculturas devem atender ao que determinam as licenças e respectivas leis e serem praticadas com o mínimo de impactos ao meio ambiente, o que parece ser inobservado pelos produtores.

Um dos principais problemas evidenciados foi a morosidade no processo de LA. Uma alternativa para sanar essa questão seria a descentralização do processo. Para isso, o IMASUL teria que delegar competências para a prefeitura do município, de forma a agilizar os processos de LA. Todavia é necessário que o poder público municipal apresente um quadro de profissionais capacitados e com conhecimento técnico para realizar essas atividades. Há ainda outros desafios inerentes à LA, como o monitoramento eficaz e fiscalização, projetos de apoio que colaborem para o desenvolvimento sustentável da piscicultura e ainda orientação e informações específicas quanto aos impactos ambientais. Assim, um trabalho de educação ambiental poderia ser desenvolvido em relação aos impactos causados pela piscicultura e ações de minimização e prevenção. Além disso, a realização de parcerias com instituições de ensino e órgãos ambientais, por meio da criação e desenvolvimento de projetos de extensão, poderia atender às necessidades específicas dos piscicultores, auxiliando em propostas para a melhoria de produção, o que contribuiria para a diminuição de impactos e maior eficiência na conservação e preservação dos recursos naturais. Nesse sentido, este trabalho ressalta a necessidade de que sejam revistas as estratégias de ação por parte dos órgãos responsáveis de fomentar as políticas públicas, voltadas para a piscicultura, principalmente em relação à LA. É evidente que, sobre o panorama da sustentabilidade, o setor ainda necessita de numerosos investimentos. 


\section{AGRADECIMENTOS}

Agradecemos à Msc. Kátia Garicoix e Fernando Cavalcante Canonice, pela ajuda na coleta de dados, e à Dra. Elaine Antoniassi L. Kashiwaqui pelas valiosas sugestões.

\section{REFERÊNCIAS}

APPOLO, C. B.; NISHIJIMA, T. Educação ambiental voltada à piscicultura praticada por pequenos produtores rurais. Revista Eletrônica em Gestão, Educação e Tecnologia Ambiental, v. 2, n. 2, p. 214-224, 2011.

ARAÚJO R.; MORAES, A.J.N. Diagnóstico da piscicultura nos municípios de Bocaína e Sussuapara - Piauí. In: SIMPÓSIO DE PRODUÇÃO CIENTÍFICA E SEMINÁRIO DE INICIAÇÃO CIENTÍ́FICA DA UESPI, 10., 2010. Anais... Teresina, PI: [s.n.], 2010. 16p.

BALDISSEROTTO, B. Piscicultura continental no Rio Grande do Sul: situação atual, problemas e perspectivas para o futuro. Ciência Rural, v. 39, n. 1, p. 291-299, 2009.

BATISTA, A. A contribuição da piscicultura para as pequenas propriedades rurais em Dourados-MS. 2013. Dissertação. Universidade Federal da Grande Dourados, Dourados, MS.

BIUDES, J. F. V.; CAMARGO, A. F. M. Uso de macrófitas aquáticas no tratamento de efluentes de aquicultura. Boletim da Associação Brasileira de Limnologia. Disponível em: <http://www.ablimno.org.br/boletins/pdf/bol_38(2-1).pdf>. Acesso em: 10 abr. 2015.

BRASIL. Constituição. Lei federal no ${ }^{\circ}$ 6.938, de 31 de agosto de 1981. Dispõe sobre a Política Nacional do Meio Ambiente, seus fins e mecanismos de formulação e aplicação, e dá outras providências. Diário Oficial da República Federativa do Brasil, Brasília, v. 31, 1981. 
CARVALHO, R.; LEMOS, R. Aquicultura e consumo de carnes no Brasil e no mundo. Panorama da Aquicultura, v. 19, p. 15-23, 2009. Disponível em: < http://www. panoramadaaquicultura.com.br/paginas/paginas/09_validate/?Edicao $=112>$. Acesso em: 15 out. 2014.

CASTRO, L. T.; MAFUD, M. D.; SCARE, R. F. Análise da competitividade do APL de piscicultura no Lago de Três Marias. Organizações rurais \& agroindustriais, Lavras, v. 13, n. 3, p. 389-402, 2011.

CYRINO, J. E. P.; BICUDO, A. J. A.; SADO, R. Y.; BORGHESI, R.; DAIRIKI, J. K. A piscicultura e o ambiente: o uso de alimentos ambientalmente corretos em piscicultura. Revista Brasileira de Zootecnia, v. 39, p. 68-87, 2010.

CONAMA. Conselho Nacional do Meio Ambiente. Resolução n ${ }^{\circ} 413$, de 26 de junho de 2009 - Dispõe sobre o licenciamento ambiental da aquicultura, e dá outras providencias. Diário Oficial da União. Brasília, 30 de jun. de 2009.

CONAMA. Conselho Nacional do Meio Ambiente. Resolução. 237/97. de 19/12/1997. Regulamenta os aspectos de licenciamento ambiental estabelecidos na Política Nacional do Meio Ambiente. Diário Oficial da União, Brasília, 22 de dez. de1997.

DELARIVA, R. L.; AGOSTINHO, A. A. Introdução de espécies: uma síntese comentada. Acta Scientiarum. Biological Sciences, v. 21, p. 255-262, 1999.

DOTTI, A.; VALEJO, P. A. P; RUSSO, M. R. Licenciamento ambiental na piscicultura com enfoque na pequena propriedade: uma ferramenta de gestão ambiental. Revista Ibero-Americana de Ciências Ambientais, v. 3, n. 1, p. 6-16, 2012.

DUTRA, F. M. Análise da estrutura, conduta e desempenho da cadeia produtiva do peixe no município de Dourados/MS. 2014. Dissertação. Universidade Federal da Grande Dourados, Dourados, MS.

GOMES, P. M; MELO, C.; VALE, V. S. Avaliação dos impactos ambientais em nascentes na cidade de Uberlândia-MG: análise macroscópica. Sociedade \& Natureza, v. 17, n. 32, p. 103-120, 2005. 
GUILHOTO, J. J.M; ICHIHARA, S. M.; SILVEIRA, F. G.; DINIZ, B. P. C.; AZZONI, C. R; Moreira, G. R. C. A importância da agricultura familiar no Brasil e em seus estados. Brasília: NEAD, 2007.

HENRY-SILVA, G. G.; CAMARGO, A. F. M.. Impacto das atividades de aqüicultura e sistemas de tratamento de efluentes com macrófitas aquáticas-relato de caso. Boletim do Instituto de Pesca, São Paulo, v. 34, n. 1, p. 163-173, 2008.

IBGE.InstitutoBrasileirodeGeografiaeEstatística.Disponívelem: < www.ibge.gov.br/ munic2012/ver_tema.php?tema $=$ t10_3\&munic $=500568 \&$ uf $=\&$ nome $=$ mundo novo >. Acesso em: 23 jul. 2014.

INOUE, A. K. A. L.; BOUJINK, L. C. Manaus a capital do tambaqui. Embrapa Amazonia, 2011. Disponível em: < http:// www.infobibos.com/Artigos/2011_1/ tambaqui/index.htm > . Acesso em: 16 dez. 2016.

LIMA-JUNIOR, D. P.; PELICICE, F. M.; VITULE, J. R.; AGOSTINHO, A. A. Aquicultura, política e meio ambiente no Brasil: Novas propostas e velhos equívocos. Natureza \& Conservação, v. 10, p. 88-91, 2012.

LANGEANI, F.; CORRÊA E CASTRO, R. M.; OYAKAWA, O. T.; SHIBATTA, O. A.; PAVANELLI, C. S.; CASATTI, L. Diversidade da ictiofauna do Alto Rio Paraná: composição atual e perspectivas futuras. Biota Neotropica, v. 7, n. 3, p. 1-17, 2007.

MACEDO, C. F.; SIPAÚBA-TAVARES, L. H. Eutrofização e qualidade da água na piscicultura: Consequências e recomendações. Boletim do Instituto de Pesca, v. 36, n. 2, p. 149-163, 2010.

MALLASEN, M.; CARMO, C. F.; TUCCI, A.; BARROS, H. P.; ROJAS, N. E. T.; FONSECA, F. S.; YAMASHITA, E. Y. Qualidade da água em sistema de piscicultura em tanques rede no reservatório de Ilha Solteira, SP. Boletim do Instituto de Pesca, São Paulo, v. 38, n. 1, p. 15-30, 2012.

PIMENTA, P. P. P. A viabilidade da piscicultura para o pequeno produtor de Dourados. Comunicação \& Mercado, v. 1, n. 1, p. 36, 2012. 
PRODANOV, C. C.; FREITAS, E. C. Metodologia do Trabalho Científico: Métodos e Técnicas da Pesquisa e do Trabalho Acadêmico. 2. ed. [s.l.]: Feevale, 2013.

RESENDE, E. K. As perspectivas da piscicultura em Mato Grosso do Sul. Corumbá, MS: Embrapa Pantanal, 2007.

ROTTA, M. A. Diagnóstico da piscicultura na Bacia do Alto Taquari-MS. Embrapa Pantanal. Boletim de Pesquisa e Desenvolvimento, 2003. Disponível em: <http:/www.cpap. embrapa.br/publicacoes/online/BP40.pdf>. Acesso em: 20 dez. 2014.

SAMPAIO, F. G.; LOSEKANN, M. E.; BARRETO LUIZ, A. J.; NEVES, M. C.; FRASCÁSCORVO, C. M. D.; RODRIGUES, G. S. Monitoramento e gestão ambiental da piscicultura em tanques-rede em reservatórios. Informe Agropecuário, Belo Horizonte, v. 34, n. 272, p. 1-11, 2013.

SCORVO-FILHO, J. D. Panorama da aquicultura nacional. Informes TécnicosAssociação Catarinense de Aquicultura, 2003.

SEBRAE. Serviço Brasileiro de Apoio à Micro e Pequenas Empresas. Licenciamento ambiental da aquicultura: critérios e procedimentos. 2011. Disponível em: < http:// wwrezenw.sebrae.com.br/sites/PortalSebrae/artigos/Licenciamento-ambiental-daaquicultura:-crit\%C3\%A9rios-e-procedimentos > . Acesso em: $10 \mathrm{dez} .2014$.

SEMAC. Secretaria de Estado de Meio Ambiente. Resolução n.008, de 31 de maio de 2011. Estabelece normas e procedimentos para o licenciamento ambiental Estadual, e dá outras providências. Diário oficial do Estado, № 7.962 de 02 de maio de 2011.

SILVA, P.C; KRONKA, S. N.; TAVARES, L. H. S.; SOUZA, V. L. Desempenho produtivo da tilápia do Nilo (Oreochromis niloticus L.) em diferentes densidades e trocas de água em "raceway". Acta Scientiarum Animal Sciences, v. 24, p. 935-941, 2008.

SOARES, C. Análise das implicações sociais, econômicas e ambientais relacionadas ao uso da piscicultura: o caso Fazenda Princesa do Sertão. 2003. Dissertação (Mestrado) - Universidade Federal de Santa Catarina, 2003.

TAKAHASHI, F.; LEÃO, F. R.; CAMPEÃO, P. Arranjo Produtivo Local: O Caso da Piscicultura na Região de Dourados/Ms. Revista em Agronegócio e Meio Ambiente, 
v. 1, n. 3, p. 327-334, 2008.

VALENTI, W. C. Aquicultura sustentável. In: CONGRESSO DE ZOOTECNIA, 12., 2002. Anais... Vila Real Portugal: Associação portuguesa dos Engenheiros Zootécnicos. 2002.

ZANIBONI FILHO, E. Tratamento de efluentes da piscicultura. In: ZOOTEC, Campo Grande, MS. Anais... [s.l.; s.n.], 2005.

Recebido em: 10 de setembro de 2015 Aceito em: 18 de fevereiro de 2017 